\begin{tabular}{|c|c|c|c|c|c|c|c|}
\hline & Mean & Median & Mode & Variance & $\begin{array}{l}\text { Standard } \\
\text { deviation }\end{array}$ & $\begin{array}{c}\text { Interquartile } \\
\text { range }\end{array}$ & $\begin{array}{l}\text { Curtosis } \\
\text { (STD) }\end{array}$ \\
\hline $\begin{array}{l}\text { SIMPLICITY } \\
\text { (1: Too difficult; } 7 \text { : Very }\end{array}$ & 5.4927 & 5.0 & 7.0 & 2.2610 & 1.5037 & ronge & 0.8358 \\
\hline * The user is the patient & 5.3453 & 5.0 & 6.0 & & & & \\
\hline $\begin{array}{l}\text { * The user is the care } \\
\text { provider }\end{array}$ & 5.5564 & 5.0 & 7.0 & & & & \\
\hline $\begin{array}{l}\text { *The user is the patient } \\
\text { and the care provider. }\end{array}$ & 5.6648 & 5.0 & 6.0 & & & & \\
\hline $\begin{array}{l}\text { TIME CONSUMPTION } \\
\text { (1: Not significant ; } 7 \text { : Too } \\
\text { much) }\end{array}$ & 3.4341 & 3.0 & 3.0 & 2.5911 & 1.6176 & 2.0 & 0.0678 \\
\hline $\begin{array}{l}\text { USEFULNESS (1: None; } 7 \text { : } \\
\text { Very useful). }\end{array}$ & 5.4585 & 6.0 & 7.0 & 2.1319 & 1.4601 & 2.0 & 1.5696 \\
\hline $\begin{array}{l}\text { USEFULNESS OF THE } \\
\text { PAPER MODEL (1: None; } \\
\text { 7: Very useful). }\end{array}$ & 4.3902 & 5.0 & 5.0 & 3.5626 & 1.8875 & 3.0 & -0.9363 \\
\hline
\end{tabular}

Disclosure of Interest: None declared

DOI: 10.1136/annrheumdis-2017-eular.5182

\section{AB1080 RESULTS IN THE FOLLOW-UP OF THE NURSING CONSULTATION FOR THE MONITORING OF RHEUMATOLOGIC PATIENTS TREATED WITH INTRAVENOUS THERAPIES}

C. Nájera Herranz ${ }^{1}$, I. Cánovas OImos ${ }^{1}$, J. Ivorra Cortes ${ }^{1}$, E. Grau Garcia ${ }^{1}$, C. Alcañiz Escandell ${ }^{1}$, K. Arévalo Ruales ${ }^{1}$, I. Chalmeta Verdejo ${ }^{1}$, C.M. Feced Olmos $^{1}$, J.J. Fragio Gil ${ }^{1}$, R. González Mazarío ${ }^{1}$, L. Gonzalez Puig ${ }^{1}$, E. Labrador Sánchez ${ }^{1}$, I. Martínez Cordellat ${ }^{1}$, R. Negueroles Albuixech ${ }^{1}$, J.E. Oller Rodriguez ${ }^{1}$, F.M. Ortiz-Sanjuan ${ }^{1}$, E. Vicens Bernabeu ${ }^{1}$, D. Hervás Marín ${ }^{2}$, J.A. Román Ivorra ${ }^{1} .{ }^{1}$ Rheumatology Department, HUP la Fe; ${ }^{2}$ Biostatistics Unit, IIS la Fe, Valencia, Spain

Background: In the management of rheumatologic patients treated with intravenous therapies, its regular monitoring is recommended in order to ensure its safety. The Nursing Consultation for monitoring rheumatologic patients treated with Intravenous Therapies (NCIT) represents a major support to patient caring for it provides patient monitoring before treatment administration and prior to rheumatologist consultation.

Objectives: To analyze number and types of incidents detected in the NCIT.

Methods: A cross-sectional longitudinal, observational study of data from patients followed-up in the NCIT (which was initiated in 2012) was performed. We have collected data of gender, diagnosis, drug administered, incidents detected previously to the drug administration, and if the incident was detected by telephone (one day before drug administration) or by personal interview. Biostatistical analysis with $\mathrm{R}$ (3.3.2.) was performed.

Results: We analyzed 7809 drug infusions corresponding to 545 patients $(73 \%$ women). $48.25 \%$ of patients were diagnosed with osteoporosis (OP), $30.1 \%$ rheumatoid arthritis (RA), $5.7 \%$ ankylosing spondylitis (AS), $4.2 \%$ systemic lupus erythematous (SLE), 2.9\% psoriatic arthritis (PsOA) and $8.3 \%$ had other diagnosis. The intravenous therapies were antiosteoporotic drug $(7.8 \%)$ and biological and immunosuppressive treatment, being the most common drugs tocilizumab (38.89\%), infliximab (31.9\%) and abatacept (18.05\%). In the 7809 treatment infusions, 477 incidents $(4.1 \%)$ were registered, 33 of them related to the antiosteoporotic therapies and the other 444 incidents (93\%) occurred in the biological therapies. The $63.7 \%$ of the incidents were detected by telephone one day before drug infusion. Statistical analysis showed that SLE patients exhibit higher tendency to incidents $(4.8 \%$ of incidents in the 392 treatments for SLE patients; $P=0.026)$ than other autoimmune diseases. On the other hand, RA and AS patients have incidents detected mainly by telephone ( $P=0.047$ y $P=0.029$ respectively). We also observed a high number of incidents in the intravenous administration of TCZ ( $P=0.009)$.

Conclusions: The NCIT has performed the follow-up of more than 500 patients with only $6 \%$ of incidents, contributing to an improvement in the patients' health and in its caring. Moreover, the fact of identifying the incidents helps to reduce the number of personal consultations, avoids drug preparation in those cases where this infusion is suspended, and in summary it improves management of hospital resources.

Disclosure of Interest: None declared

DOI: 10.1136/annrheumdis-2017-eular.5702

\section{AB1081 INTEGRATING CASE FINDING AND INITIAL MANAGEMENT FOR OSTEOARTHRITIS, ANXIETY AND DEPRESSION INTO ROUTINE PRIMARY CARE NURSE-LED LONG-TERM CONDITION REVIEWS: RESULTS FROM THE ENHANCE PILOT TRIAL}

C. Jinks ${ }^{1}$, E. Nicholls ${ }^{1,2}$, J. Liddle ${ }^{1}$, E.L. Healey ${ }^{1}$, A.L. Evans ${ }^{1}$, C.A. Chew-Graham ${ }^{1}$, K.S. Dziedzic ${ }^{1}$, V.A. Tan ${ }^{1}$, A.G. Finney ${ }^{1}$, M. Porcheret ${ }^{1}$ S. Lawton ${ }^{2}$, V. Cooper ${ }^{1}$, M. Lewis ${ }^{1,2}$, C.D. Mallen ${ }^{1}$ on behalf of ENHANCE team. ${ }^{1}$ Research Institute for Primary Care \& Health Sciences; ${ }^{2}$ Keele Clinical Trials Unit, Keele University, Keele, United Kingdom

Background: Co-morbid osteoarthritis (OA), anxiety and depression are undermanaged in primary care yet have significant impact on pain, disability and outcomes of other long-term conditions (LTCs).

Objectives: To test the feasibility and acceptability of integrating case-finding and initial management for $\mathrm{OA}$, anxiety and depression within extended primary care practice nurse (PN)-led LTC review consultations.
Methods: A stepped wedge pilot trial with process evaluation. PNs gave a study pack to patients age $\geq 45$ years attending routine LTC reviews (asthma, COPD, hypertension, ischaemic heart disease, diabetes). The intervention included case finding questions (Generalized Anxiety Disorder (GAD2), Whooley 2-item depression, diagnosing OA clinically (hands, hips, knees or feet)) followed by further assessments (anxiety (GAD7), depression (PHQ9), joint examination). PNs completed an electronic patient record and initiated management. Predetermined success criteria were to recruit 4 practices; deliver training to 2 PNs per practice, recruit $50 \%$ of those invited, ensure $75 \%$ follow up (6 week, 6 month), and the satisfaction (GPAQ) of intervention patients to be at least as acceptable as that of control patients. 24 audio recorded consultations provided insight into fidelity of intervention delivery.

Results: Four practices were recruited. PNs were sequentially trained in practice prior to switching to intervention. Of the 474 people invited, 319 responded (207 control, 112 intervention) (67\%). $83 \%$ and $79 \%$ of participants returned 6 week and 6 month questionnaires respectively. Demographic characteristics, general health, pain intensity, anxiety and depression scores were similar across arms. Overall, self-reported health (EQ5D5L) was high (median 0.84; IQR 0.72, 0.94). $14 \%$ of participants reported moderate to severe depression (PHQ9). Median GPAQ scores were similar (control 1.00 (IQR: 1.00, 1.29), intervention 1.00 (IQR: $1.00,1.14)) .96 \%$ of those in the intervention arm reported being asked about joint pain, $93 \%$ reported being asked about mood. Audio recordings revealed that case finding questions were used as intended in most consultations (joint pain 20/24 consultations, anxiety 15/24, depression 6/24). One referral to physiotherapy and none to primary care mental health services were recorded by the PNs.

Conclusions: Recruitment and follow up were good. However, to target those who may benefit from the intervention, changes to the target population and eligibility criteria are required. There was reasonable delivery of the case finding questions, but limited referral and signposting, highlighting areas to optimise ahead of a main trial.

Acknowledgements: ELH, CJ, CCG, ALE and CDM are part funded by NIHR Collaborations for Leadership in Applied Health Research and Care West Midlands. CDM is funded by NIHR School for Primary Care Research, NIHR Research Professorship in General Practice (NIHR-RP-2014-04-026). KSD is part-funded by an NIHR Knowledge Mobilisation Research Fellowship (KMRF2014-03-002). Views expressed in this paper are those of the author(s) and not necessarily those of the NHS, the NIHR, or the Department of Health.

Disclosure of Interest: None declared

DOI: 10.1136/annrheumdis-2017-eular.2473

\section{AB1082 IMPACT OF ANKYLOSING SPONDYLITIS VERSUS NON-RADIOGRAPHIC SPONDYLOARTHRITIS ON EARLY RETIREMENT}

C. Cobilinschi, R. Ionescu, D. Opris-Belinski. Sfanta Maria Clinical Hospital, Bucharest, Romania

Background: Axial spondyloarthritis include non-radiographic SpA (nr-SpA) and ankylosing spondylitis (AS), suggesting the extent of sacroiliac involvement on imaging techniques (1). The influence of the two conditions on patients' physical function and their impact on work capacity should be regularly assessed so that we can better contribute to patients' social integration.

Objectives: The present study aims to assess the differences between AS and $\mathrm{nr}-\mathrm{SpA}$ patients under anti-TNF therapy regarding disease related retirement (DR) and its contributing factors.

Methods: Over a period of eleven months 136 patients diagnosed with AS or nr-SpA on current biological therapy were included. Demographic data and working status were assessed. Statistical analysis was performed with SPSS 20.0.

Results: In the study cohort $69 \%$ of patients were males. The predominant age group was situated between 30 to 40 years old $(29.8 \%)$, while $20.2 \%$ were over 50 . Out of the study group, $66 \%$ confirm they are active in their work field with a minimum of seven hours per day, whereas $4.3 \%$ reached their retirement age. $29.8 \%$ of patients were granted a disability retirement and the majority $(42.9 \%)$ belonged to the $40-50$ age group. Surprisingly, $6.8 \%$ of early retired patients were under 30 . Out of the DR category, $92.9 \%$ were diagnosed with AS, while the rest of $7.1 \%$ had $\mathrm{nr}-\mathrm{SpA}$. The interval from diagnosis to the initiation of biological therapy was $72.5 \pm 85.1$ months for AS patients and $64.1 \pm 71.2$ for nr-SpA. $23.2 \%$ of patients applied for early retirement before biological therapy and only $3.1 \%$ resumed work after anti-TNF introduction. Patient gender did not influence the working capacity. At the time of study inclusion, $12 \%$ of patients with AS and $4 \%$ of patients with nr-SpA still exhibited signs of highly active disease, according to ASDAS-CRP assessment.

Conclusions: Almost a third of patients in the study group were offered early retirement due to axial $\mathrm{SpA}$. The vast majority of disease related retirement patients were known with AS, thus emphasizing the extent of disability brought on by this entity. However, a significant percentage of patients suffered from $\mathrm{nr}-\mathrm{SpA}$, raising doubts as to whether clinicians can promptly diagnose this entity and offer early, appropriate treatment so that inability no longer occurs.

\section{References:}

[1] Wendling D, Prati C, Claudepierre P, Guillot X, Breban M. Non-radiographic spondyloarthritis: A theoretical concept or a real entity? Jt Bone Spine. 2012. Disclosure of Interest: None declared 